Military Technical College Cairo, Egypt

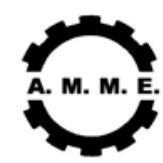

$12^{\text {th }}$ International Conference on Applied Mechanics and Mechanical Engineering (AMME)

\title{
TORSIONAL DYNAMIC OPTIMIZATION OF WIND POWER GENERATORS
}

\author{
KARAM Y. MAALAWI
}

\begin{abstract}
The present paper develops an appropriate optimization model for placing frequencies of a typical wind rotor/tower structure in free torsional motion. The aim is to avoid large amplitudes caused by the yawing-induced vibrations in the case of horizontal-axis machines or rotational motion of the blades about the tower axis in case of vertical-axis machines. This can be a major cause of fatigue failure and might severely damage the whole structure of the wind generator. The mathematical formulation considers a single pole tower configuration having thin-walled circular cross section with constant taper along the tower height. The nacelle/rotor combination is modeled as a rigid mass elastically supported at the top of the tower by the torsional spring of the yawing mechanism. The resulting governing differential equation of motion is solved analytically by transforming it into a standard form of Bessel's equation, which leads to the necessary exact solutions for the frequencies and mode shapes. Several cases of study are examined for different values of the yawing stiffness and damping parameters by considering both conditions of locked and unlocked yawing mechanism. Useful design charts are developed for placing the frequencies at their needed target values with no penalty of increasing the total structural weight of the system. In all, the developed model guarantees full separation of the system frequencies from the critical exciting torsional frequencies by the appropriate choice of the optimization design parameters.
\end{abstract}

\section{KEYWORDS}

Structural dynamics, Design optimization, Wind turbines.

\footnotetext{
"Associate professor, Dpt. Of Mechanical Engineering, National Research Center, Dokki, Cairo, Egypt.
} 


\section{NOMENCLATURE}

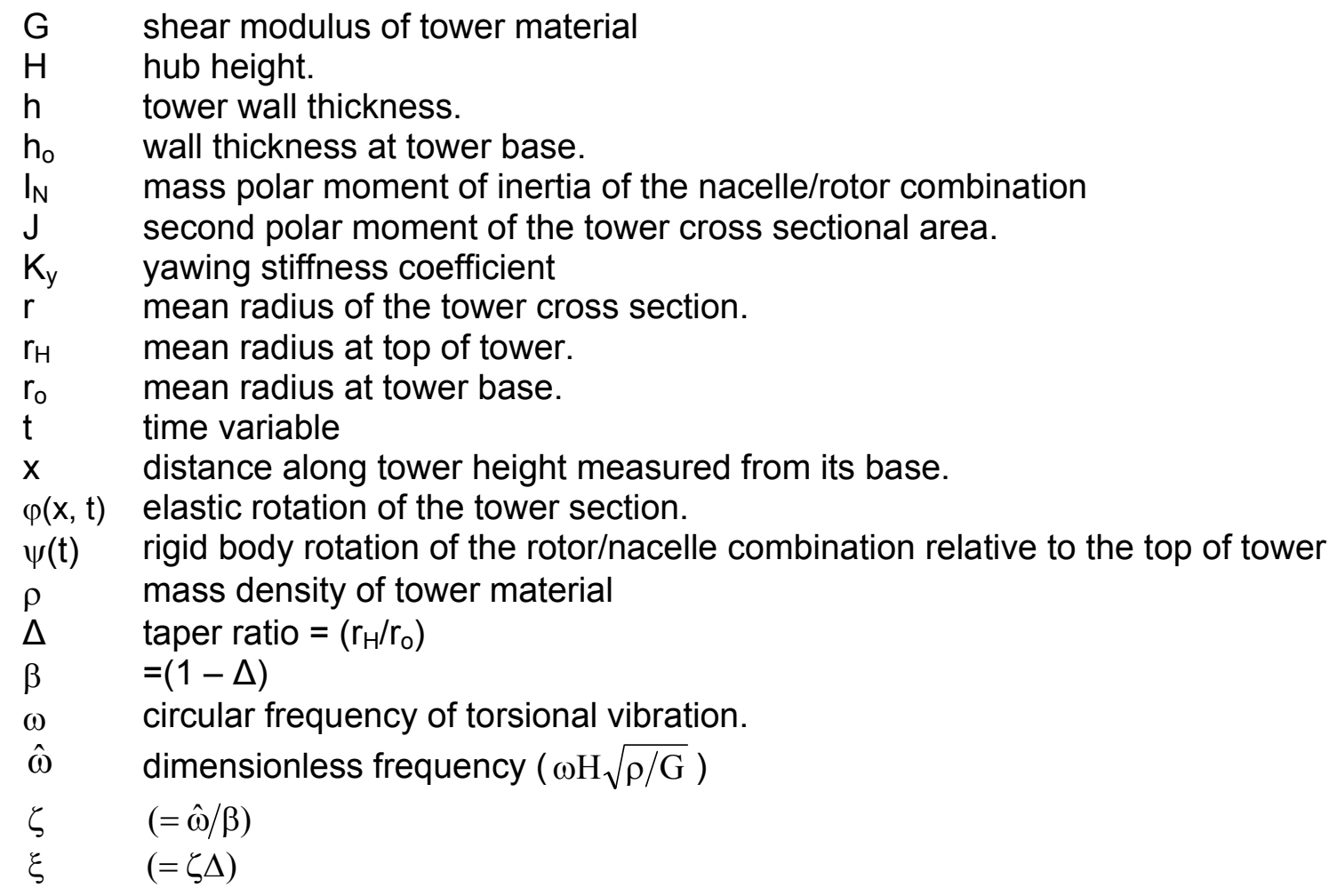




\section{INTRODUCTION}

One of the most important aspects of $R \& D$ in the wind energy programs is the accuracy of analyzing structural dynamics of wind turbines; a crucial factor in determining fatigue life of the machine. Research is continuing for a better investigation of the dynamic interactions between the rotor, nacelle and the tower structures. A recent paper dealing with this issue and the simulation of wind turbine dynamics was presented by Florin lov et al [1], who developed different tools for performing the analysis of the interaction between the mechanical system of the wind turbine and the electrical grid as well as the calculation of the dynamic loads on the turbine structure. In case of horizontal-axis machines, the rotation of the nacelle/rotor combination with respect to the tower axis is an important degree of freedom in wind turbine dynamics. Such a rigid body motion is produced by the yawing mechanism to direct the rotor towards the wind in order to maximize energy capture [2, 3]. Usually this is accomplished actively with an electrical or hydraulic yaw servo. A wind vane, placed on top of the nacelle, senses the wind direction. The servo is activated when the mean relative wind direction exceeds some predefined limits. Therefore, the wind machine spends much of its time yawed, so it would seem reasonable to expect that designs should have a sufficient understanding of the response of the turbine in that condition to take it properly into account. There are frequent yaw system failures world-wide on wind turbines, where some statistical studies [4] indicated that such failures accounts for about $10-15 \%$ of breakdowns in any given year the wind plant is in operation. This fact emphasizes the need to improve the design of yaw mechanisms in order to increase the availability of turbines and reduce their maintenance overheads. One of the most cost-effective solutions in designing efficient yaw mechanisms and reducing the produced vibrations is to separate the natural frequencies of the tower/nacelle/rotor structure from the critical exciting yawing frequencies. This would avoid resonance where large amplitudes of vibration could severely damage the whole structure. The frequency-placement technique $[5,6]$ is based on minimizing an objective function constructed from a weighted sum of the squares of the differences between each important frequency and its desired (target) value. Approximate values of the target frequencies are usually chosen to be within close ranges; sometimes called frequency-windows; of those corresponding to a reference baseline design, which are adjusted to be far away from the critical exciting frequencies. Direct maximization of the system natural frequencies is also favorable for increasing the overall stiffness-to-mass ratio level of the structure being excited [7-9]. This may further other design objectives such as higher stability and fatigue life and lower cost and noise levels. Practical models of beam structures were formulated in Ref.[10], where dynamic analysis and structural design were performed simultaneously by finite element method coupled with constrained optimization algorithm.

The scope of the present work is to perform first the necessary exact dynamical analysis of a practical model of the wind turbine in order to be able to place the frequencies at their target values. Secondly, the behavior of the yawing fundamental frequency will be investigated in detail to see how it changes with the selected design variables. Cases of study include the locked and unlocked conditions of the yawing mechanism. Design variables encompass the cross-sectional properties of the tower and its tapering ratio, as well as the yawing stiffness and the rotor/nacelle 
inertia ratios. It is demonstrated that global optimality can be achieved from the proposed model and an accurate method for the exact placement of the system natural frequencies is deduced.

\section{GOVERNING EQUATION OF MOTION}

The system to be analyzed is illustrated in Fig.1. The rotor/nacelle combination is considered as a rigid body with mass polar moment of inertia $I_{N}$ spinning about the vertical axis, $\mathrm{X}$, at an angular displacement $\psi(\mathrm{t})$ relative to the top of the tower. The tower is in the state of free torsional vibration about its centroidal axis with an absolute angular displacement denoted by $\varphi(x, t)$. The yawing mechanism is assumed to have a linear torsional spring with a stiffness $\mathrm{K}_{\mathrm{y}}$. Applying the elementary theory of torsion [11], the governing equation of the motion is cast in the following:

$$
\frac{\partial}{\partial x}\left[G J(x) \frac{\partial \varphi(x, t)}{\partial x}\right]=\rho I_{p}(x) \frac{\partial^{2} \varphi(x, t)}{\partial t^{2}}
$$

subject to the boundary conditions:

at the tower base $(\mathrm{x}=0) \quad \varphi(0, \mathrm{t})=0$

$$
\left.\underline{\text { at the top of tower }(\mathrm{x}=\mathrm{H})} \quad \mathrm{GJ} \frac{\partial \varphi}{\partial \mathrm{x}}\right|_{\mathrm{x}=\mathrm{H}}=\mathrm{K}_{\mathrm{y}} \psi(\mathrm{t})=-\mathrm{IN}_{\mathrm{N}}\left(\frac{\partial^{2} \varphi}{\partial \mathrm{t}^{2}}+\frac{\mathrm{d}^{2} \psi}{\mathrm{d} \mathrm{t}^{2}}\right)
$$

where $G J(x)$ and $\rho l_{p}(x)$ represent the torsional stiffness and the mass polar moment of inertia per unit length, respectively. The twisting angle $\varphi(x, t)$ is assumed to be separable in space and time, $\varphi(x, t)=\Phi(x) \cdot q(t)$, where the time dependence $q(t)$ is harmonic with circular frequency $\omega$.

The associated eigenvalue problem can be written directly in the form

$$
\frac{d}{d x}\left[G J(x) \frac{d \Phi}{d x}\right]+\rho I_{p}(x) \omega^{2} \Phi(x)=0
$$

The boundary conditions are obtained by substituting for $\frac{\mathrm{d}^{2} \mathrm{q}}{\mathrm{dt}^{2}}=-\omega^{2} \mathrm{q}$ in Eq. (1.3) to get:

$$
\begin{array}{ll}
\text { at } \mathrm{x}=0 & \Phi(\mathrm{x})=0 \\
\text { at } \mathrm{x}=\mathrm{H} & \frac{\mathrm{GJ}}{\psi_{\mathrm{o}}} \frac{\mathrm{d} \Phi}{\mathrm{dx}}-\mathrm{K}_{\mathrm{y}}=0
\end{array}
$$




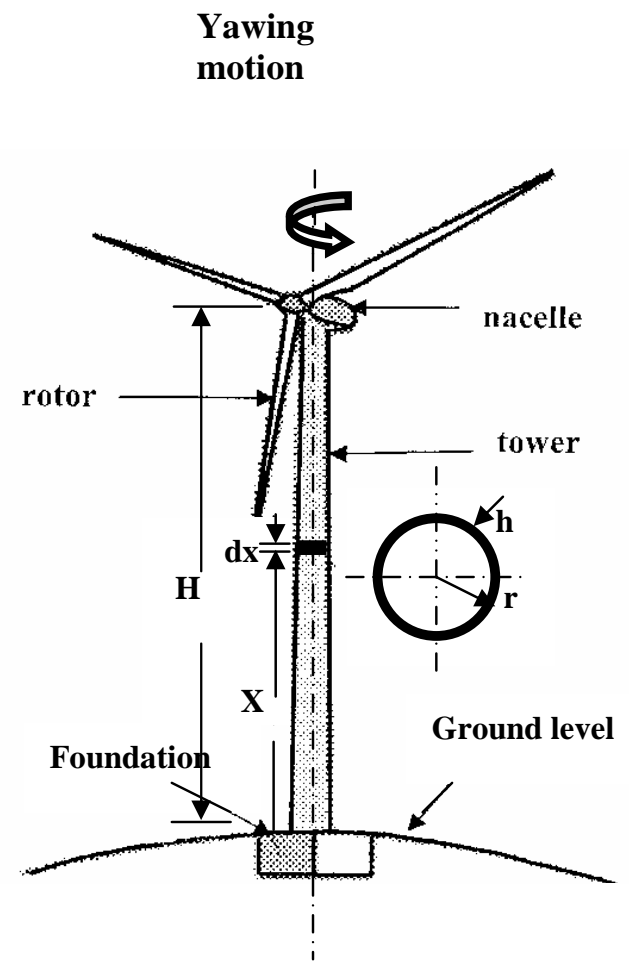

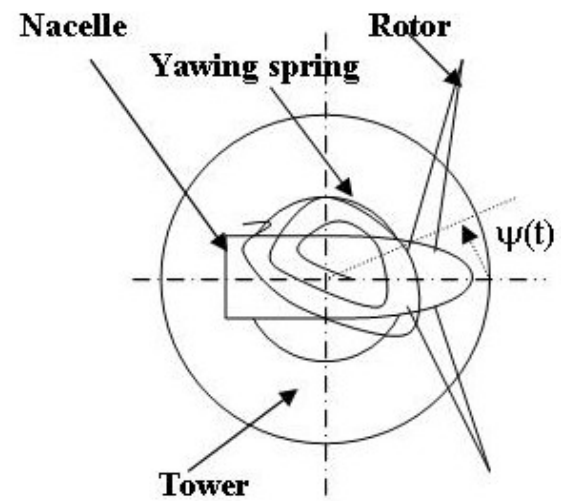

$\underline{\text { Plan view }}$

Fig.1. Horizontal-axis wind turbine in free yawing motion.

where

$$
\psi_{\mathrm{o}}=\left[\frac{\mathrm{GJ}}{\omega^{2} \mathrm{I}_{\mathrm{N}}} \frac{\mathrm{d} \Phi}{\mathrm{dx}}-\Phi\right]
$$

Considering a tapered tower with thin-walled circular cross section (refer to Fig.1):

$$
J=I_{p}=2 \pi r^{3} h
$$

where $r$ and $h$ are assumed to have the same linear distribution described by the expressions:

$$
\begin{aligned}
& r=r_{o}(1-\beta \hat{x}) \\
& h=h_{o}(1-\beta \hat{x})
\end{aligned}
$$

$\hat{\mathrm{x}}$ and $\beta$ are dimensionless parameters defined as:

$$
\hat{\mathrm{x}}=\frac{\mathrm{x}}{\mathrm{H}}, \beta=(1-\Delta), \Delta=\mathrm{r}_{\mathrm{H}} / \mathrm{r}_{\mathrm{o}}
$$

where $\boldsymbol{\Delta}$ is the taper ratio of the tower. Substituting in Eq. (3.1), the second polar moment of the cross sectional area becomes

$$
J=2 \pi r_{0}^{3} h_{o}(1-\beta \hat{x})^{4}
$$




\section{SOLUTION PROCEDURE}

Introducing the transformation $\quad \hat{\mathrm{x}}=\frac{1}{\beta}-\frac{1}{\hat{\omega}} \mathrm{y}$

Eq. (5) takes the form

$$
\mathrm{J}=2 \pi \mathrm{r}_{\mathrm{o}}^{3} \mathrm{~h}_{\mathrm{o}}\left(\frac{\beta}{\hat{\omega}}\right)^{4} \mathrm{y}^{4}
$$

where $\hat{\omega}=\omega \mathrm{H} \sqrt{\rho / G}$ is a dimensionless frequency parameter. Eq.(2.1) is now transformed into

$$
\frac{\mathrm{d}^{2} \Phi}{\mathrm{dy}^{2}}+\frac{4}{\mathrm{y}} \frac{\mathrm{d} \Phi}{\mathrm{dy}}+\Phi=0
$$

which can be further transformed to the standard form of Bessel's equation by setting $\Phi=(\mathrm{y})^{-3 / 2} \theta$, to get

$$
y^{2} \frac{d^{2} \theta}{d y^{2}}+y \frac{d \theta}{d y}+\left(y^{2}-\frac{9}{4}\right) \theta=0
$$

which has the solution

$$
\theta(\mathrm{y})=\mathrm{C}_{1} \mathrm{~J}_{3 / 2}+\mathrm{C}_{2} \mathrm{~J}_{-3 / 2}
$$

where $\mathrm{C}_{1}$ and $\mathrm{C}_{2}$ are constants of integration and $\mathrm{J}_{3 / 2}$ and $\mathrm{J}_{-3 / 2}$ are Bessel's functions of order $\mathrm{k}= \pm 3 / 2$, given by [12]:

$$
\begin{aligned}
& J_{3 / 2}(y)=\sqrt{\frac{2}{\pi y^{3}}(\sin y-y \cos y)} \\
& J_{-3 / 2}(y)=-\sqrt{\frac{2}{\pi y^{3}}}(\cos y+y \sin y)
\end{aligned}
$$

Table 1. Definition of dimensionless quantities

\begin{tabular}{|l|c|l|}
\hline \multicolumn{1}{|c|}{ Quantity } & Notation & \multicolumn{1}{|c|}{$\begin{array}{c}\text { Dimensionless } \\
\text { expression }\end{array}$} \\
\hline Circular frequency & $\omega$ & $\hat{\omega}=\omega \mathrm{H} \sqrt{\rho / G}$ \\
\hline Spatial coordinate & $\mathrm{x}$ & $\hat{\mathrm{x}}=\mathrm{x} / \mathrm{H}$ \\
\hline $\begin{array}{l}\text { Mean radius of tower } \\
\text { cross section }\end{array}$ & $\mathrm{r}$ & $\hat{\mathrm{r}}=\mathrm{r} / \mathrm{r}_{\mathrm{b}}$ \\
\hline Tower wall thickness & $\mathrm{h}$ & $\hat{\mathrm{h}}=\mathrm{h} / \mathrm{h}_{\mathrm{b}}$ \\
\hline $\begin{array}{l}\text { Second polar moment of } \\
\text { area }\end{array}$ & $\mathrm{J}$ & $\hat{\mathrm{J}}=\mathrm{J} / \mathrm{J}_{\mathrm{b}}\left(=\hat{\mathrm{r}}^{3} \hat{\mathrm{h}}\right)$ \\
\hline $\begin{array}{l}\text { Polar moment of inertia of } \\
\text { Nacelle/rotor mass }\end{array}$ & $\mathrm{I}_{\mathrm{N}}$ & $\hat{\mathrm{I}}_{\mathrm{N}}=\mathrm{I}_{\mathrm{N}} / \rho \mathrm{H}_{\mathrm{b}}$ \\
\hline
\end{tabular}




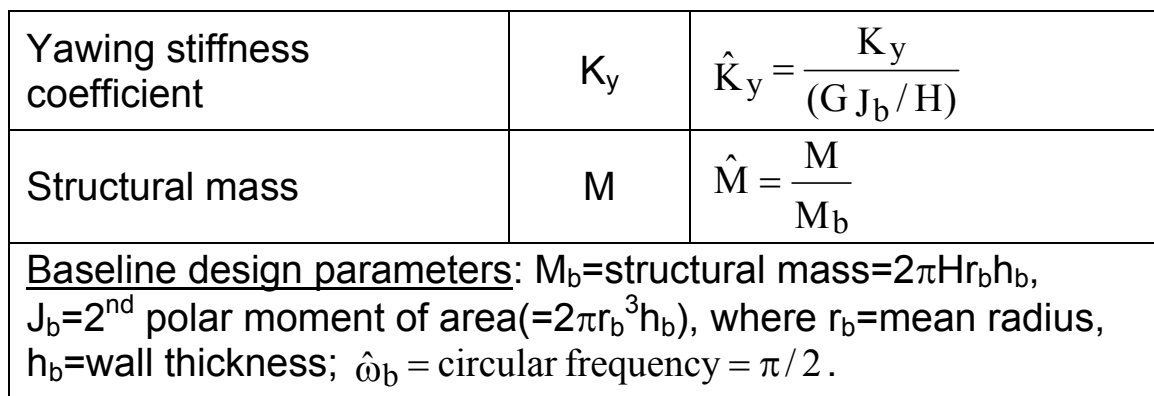

Finally, the exact analytical solution of the associated eigenvalue problem can be shown to have the form:

$$
\Phi(\mathrm{y})=\mathrm{A}\left[\frac{\mathrm{y} \cos \mathrm{y}-\sin \mathrm{y}}{\mathrm{y}^{3}}\right]+\mathrm{B}\left[\frac{\mathrm{y} \sin \mathrm{y}+\cos \mathrm{y}}{\mathrm{y}^{3}}\right]
$$

where $A$ and $B$ are constants depend on the imposed boundary conditions:

at $y=\zeta(=\hat{\omega} / \beta)$

$$
\Phi(\mathrm{y})=0
$$

at $\mathrm{y}=\xi(=\zeta \Delta)$

$$
\frac{\hat{\omega}(\mathrm{d} \Phi / \mathrm{dy})}{\psi_{\mathrm{o}}}+\left(\hat{\mathrm{K}}_{\mathrm{y}} / \hat{\mathrm{J}}\right)=0
$$

where

$$
\psi_{\mathrm{o}}=-\left[\frac{\hat{\mathrm{J}}}{\hat{\omega} \hat{\mathrm{I}}_{\mathrm{N}}} \frac{\mathrm{d} \Phi}{\mathrm{dy}}+\Phi\right]
$$

All quantities with the hat symbol $(\boldsymbol{\wedge})$ are dimensionless quantities obtained by dividing by the corresponding parameters of a baseline tower design having uniform properties and same structural mass, height and material of the optimized tower design (refer to Table 1).

Applying the boundary conditions, as described by Eqs. (10.2-3), and considering only nontrivial solution of Eq. (10.1) the frequency equation can be shown to have the following compacted form:

$$
\frac{\hat{\omega}^{2}}{\alpha \hat{\omega}+\left(\hat{J} / \hat{\mathrm{I}}_{\mathrm{N}}\right)}-\left(\hat{\mathrm{K}}_{\mathrm{y}} / \hat{\mathrm{J}}\right)=0
$$

where

$$
\alpha=\frac{\xi[\hat{\omega}-(1+\zeta \xi) \tan \hat{\omega}]}{\left(\xi^{2}-3\right)(\zeta-\tan \hat{\omega})+3 \xi(1+\zeta \tan \hat{\omega})}
$$


It is to be noted that in the above equations $\hat{\mathrm{J}}$ is the dimensionless polar moment of area at the top of tower and is equal to $\hat{\mathrm{r}}_{0}^{3} \hat{\mathrm{h}}_{\mathrm{o}} \Delta^{4}$ (refer to Eq.5). Special cases of Eq. (11) are summarized in Table 2.

Table 2. Frequency equation for some special cases

\begin{tabular}{|l|c|}
\hline \multicolumn{1}{|c|}{ Case } & Reduced frequency equation \\
\hline Locked yawing mechanism & $\alpha \hat{\omega}+\hat{\mathbf{J}} / \hat{\mathrm{I}}_{\mathrm{N}}=0$ \\
\hline Uniform tower with no taper & Apply Eq.(11.1) with $\alpha=-\tan \hat{\omega}$ \\
\hline $\begin{array}{l}\text { Stand-alone tapered tower with } \\
\text { no attached masses at the top. }\end{array}$ & {$\left[\left(3-\xi^{2}\right)+3 \zeta \xi\right] \tan \hat{\omega}-\left[3 \hat{\omega}-\zeta \xi^{2}\right]=0$} \\
\hline
\end{tabular}

Once the exact dimensionless natural frequencies have been determined the associated mode shapes can be obtained from:

$$
\Phi(\mathrm{y})=\mathrm{A}\left[\left(\frac{\mathrm{y} \cos \mathrm{y}-\sin \mathrm{y}}{\mathrm{y}^{3}}\right)-\left(\frac{\zeta-\tan \zeta}{1+\zeta \tan \zeta}\right)\left(\frac{\mathrm{y} \sin \mathrm{y}+\cos \mathrm{y}}{\mathrm{y}^{3}}\right)\right]
$$

\section{FORMULATION OF THE OPTIMUM DESIGN PROBLEM}

Attractive goals of designing efficient structures of wind generators include minimization of total cost per energy produced, minimization of structural weight and maximization of the fundamental frequencies [9, 10]. The associated optimization problems are usually cast in nonlinear mathematical programming form [13]. The objective is to minimize a function $F\left(\underline{X}_{D}\right)$ of a vector $\underline{X}_{D}$ of design variables, subject to certain number of constraints $G_{j}\left(\underline{X}_{D}\right) \leq 0, j=1,2, \ldots \ldots . M$. In the present model formulation the design variable vector is defined to be:

$$
\underline{X}_{D}=\left\{r_{0}, h_{0}, \Delta, K_{y}, I_{N}\right\}
$$

To improve the accuracy and efficiency of the numerical optimization process, and to make the model valid for a variety of wind rotor/tower configurations and material of construction, appropriate scaling and non-dimensionalization of the various parameters and variables are recommended (refer to Table 1).

The optimal design problem of the current torsional vibration of wind rotor/tower structure model may be cast in the following: 


$$
\begin{array}{ll}
\text { Minimize the objective function: } & F=\left(\hat{\omega}-\hat{\omega}^{*}\right)^{2} \\
\text { Subject to mass equality constraint: } & \hat{\mathrm{M}}=\int_{0}^{1} \hat{\mathrm{r}} \hat{\mathrm{h}} \mathrm{d} \hat{\mathrm{x}}=1 \\
\text { and the side constraints: } & \underline{\mathrm{X}}_{\mathrm{L}} \leq \underline{\mathrm{X}}_{\mathrm{D}} \leq \underline{\mathrm{X}}_{U}
\end{array}
$$

where $\omega^{*}$ is the target frequency, $\hat{\mathrm{M}}$ is the dimensionless structural mass of the tower and $\hat{r}$ and $\hat{h}$ are defined in Table 1. $\underline{X}_{L}$ and $\underline{X}_{U}$ are the lower and upper limiting values imposed on the design variables vector $\underline{X}_{D}$. Several computer program packages are available now for solving the above design optimization model, which can be coded to interact with structural and eigenvalue analyses software [14].

\section{RESULTS AND DISCUSSIONS}

The developed mathematical model has been implemented for calculating the frequencies of typical wind rotor/tower structure in free torsional motion. The target frequencies, at which the yawing frequencies needed to be close to, depend on the specific configuration and operating conditions of the wind machine. Various cases of study are examined including, tower alone and rotor/tower with both locked and unlocked yaw conditions. The main features and trends in each case are presented and discussed in this section.

\subsection{Torsional Frequencies of Tower Alone}

It is useful to consider first the case of stand-alone tower with no tip mass. This case of study can be regarded as a guide design condition with which the other conditions of locked and unlocked yawing mechanism can be compared. Fig. 2 shows the variation of the first three natural frequencies with the tapering ratio of a tower in torsional vibration. It is seen that the frequencies decrease with increasing taper. Towers having complete conical shapes shall have the maximum frequencies ( $\hat{\omega}_{1, \max }=4.4934$ for $\left.\Delta=0\right)$, which is favorable from structural design point of view. However, such configurations violate the requirement of having an adequate space at the top of the tower for supporting the wind rotor/nacelle combination. 


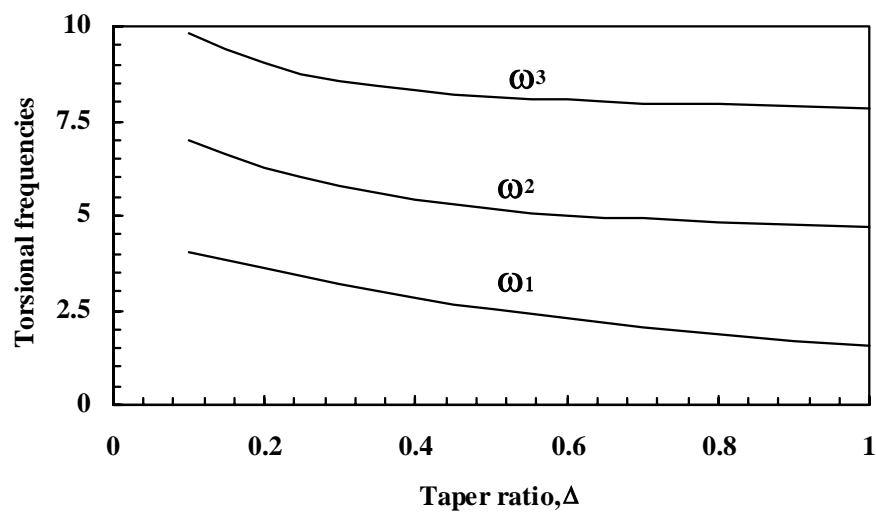

Fig.2. Torsional frequencies of tower alone

In order to place any frequency at its desired value $\omega_{\mathrm{i}}$, the first step is to calculate the dimensionless frequency $\hat{\omega}_{\mathrm{i}}$ for known properties of the tower material and hub height, and then obtain the corresponding value of the taper ratio from the curves presented in Fig. 2. The next step is to choose appropriate value for the dimensionless thickness $h_{0}$ at the tower base and find the corresponding radius of the cross section $r_{o}$ at the determined taper ratio (see Fig.3), which should satisfy the equality mass constraint expressed by the equation 14.2 .

It is to be noted here that the wall thickness $h_{0}$ shall be constrained to be greater than a preassigned lower bound, which can either be determined from the minimum available sheet thicknesses or from considerations of wall instability that might happen by local buckling. On the other hand, to insure the validity of wall thinness assumption, the selected design point $\left(r_{o}, h_{o}\right)$ should fall inside the feasible domain defined by the upper left triangle of Fig. 3 .

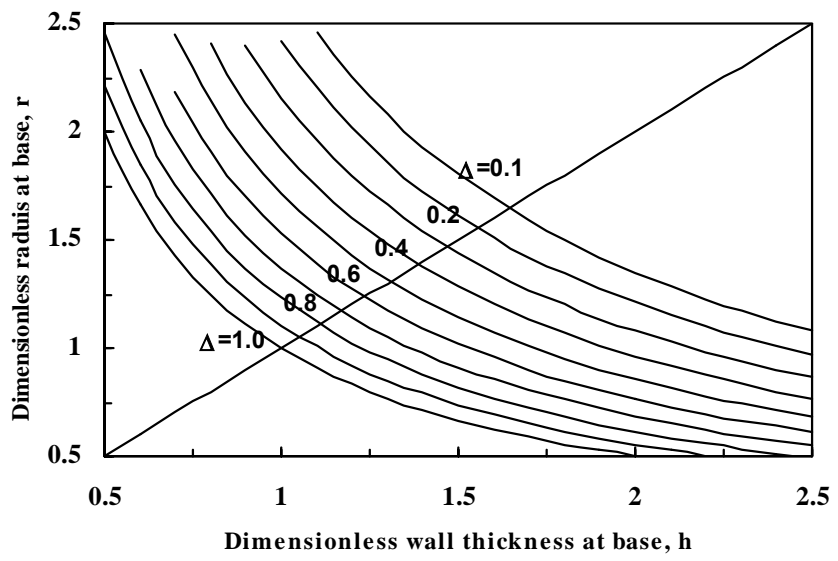

Fig. 3 Optimized tapered towers with constant mass $(\hat{\mathrm{M}}=1)$. 


\subsection{Frequency Placement of Combined Rotor/Tower Structure}

As has been mentioned before, the scope of this paper is not just to apply an optimization algorithm to find an optimum solution, which may not be the needed global solution. The main purpose, however, is to, first; perform accurate dynamic analysis in order to be able to pursue real design optimization. Secondly, the behavior of the fundamental frequency of the combined wind rotor/tower structure in free torsional vibration shall be identified thoroughly by developing its actual level curves to see how it is changed with the chosen design parameters. Figs. [4a- 4d] depict the required frequency charts for different values of $I_{N}$ of a locked yawing mechanism. Several other cases will be given in a more detailed technical report that will be available at the Department of Mechanical Engineering, National Research Center in Cairo, Egypt. It is seen from the charts that the objective function is well behaved, continuous and monotonic everywhere in the selected design space $\left(\Delta, r_{0}\right)$. Actually, the developed charts represent the fundamental frequency function augmented with the imposed mass equality constraint so that the problem may be treated as if it were an unconstrained optimization problem. The total mass is preserved at a constant value equals to that of a known baseline design. Now, it is possible to choose the desired frequency, which is far away from the excitation frequencies, and obtain the corresponding optimum variables directly from the developed frequency charts. More examination of these charts indicates that almost all of them have shown a distinct optimum zone which encompasses the global optimal solution. As the rotor/nacelle inertia increases the attained global optimum configuration changes from that one having higher thickness at tower base with low tapering ratio to a configuration with lower thickness and higher tapering ratio. Design cases for unlocked yawing mechanism are shown in Figs (5a) through (5e), where practical values of the dimensionless parameter $\hat{\mathrm{K}}_{\mathrm{y}}$ have been adopted on $\mathrm{a}$ logarithmic scale to cover a wide range of yawing stiffnesses of actual wind machines. A remarkable observation is that, as the yawing stiffness increases while keeping the rotor/nacelle inertia at a constant value, the global optimal solution moves from design points having higher values of the tapering ratio to optimal designs with fewer taper. Behavior for a fixed value of the stiffness and variable inertia has shown the same design trend of the locked condition. The maximum attainable frequencies for several design cases are summarized in Table 3 . The associated optimum values of the chosen design variables, which satisfy the imposed mass equality constraint, are also shown. As a remarkable observation, the frequency increases for increasing yawing stiffness and decreasing the rotor/nacelle inertia with a higher rate. 
Table 3. Max. Yawing frequency, $\hat{\omega}_{1, \max }$ and the corresponding design parameters $\left(\Delta, \hat{\mathrm{h}}_{0}, \hat{\mathrm{r}}_{0}\right)$ for constant mass, $\hat{\mathrm{M}}=1.0$.

\begin{tabular}{|c|c|c|c|c|}
\hline$\hat{\mathrm{K}}_{\mathrm{y}} \mathrm{i}_{\mathrm{N}}$ & 0.001 & 0.01 & 0.1 & 1.0 \\
\hline 0.01 & $\begin{array}{c}3.1625 \\
(0.6875,0.6,2.315)\end{array}$ & $\begin{array}{c}0.9988 \\
(0.8625,0.4625,2.489)\end{array}$ & $\begin{array}{c}0.316 \\
(1.0,0.4,2.5)\end{array}$ & $\begin{array}{c}0.099 \\
(1.0,0.5375,1.8605)\end{array}$ \\
\hline 0.1 & $\begin{array}{c}4.0663 \\
(0.0875,1.1,2.49)\end{array}$ & $\begin{array}{c}2.8328 \\
(0.3,0.875,2.467)\end{array}$ & $\begin{array}{c}0.9879 \\
(1.0,0.4,2.5)\end{array}$ & $\begin{array}{c}0.3137 \\
(1.0,0.4,2.5)\end{array}$ \\
\hline 1.0 & $\begin{array}{c}4.0851 \\
(0.075,1.1125,2.495)\end{array}$ & $\begin{array}{c}3.476 \\
(0.1875,0.9875,2.485)\end{array}$ & $\begin{array}{c}2.2105 \\
(0.4375,0.7375,2.497)\end{array}$ & $\begin{array}{c}0.9036 \\
(1.0,0.4,2.5)\end{array}$ \\
\hline 10.0 & $\begin{array}{c}4.0909 \\
(0.075,1.1125,2.495)\end{array}$ & $\begin{array}{c}3.5191 \\
(0.175,1.0,2.4883)\end{array}$ & $\begin{array}{c}2.4859 \\
(0.375,0.8,2.474)\end{array}$ & $\begin{array}{c}1.4122 \\
(0.7625,0.5125,2.497)\end{array}$ \\
\hline $\begin{array}{c}(\infty) \\
\text { Locked }\end{array}$ & $\begin{array}{c}4.0915 \\
(0.075,1.1125,2.495)\end{array}$ & $\begin{array}{c}3.5241 \\
(0.175,1.0,2.4883)\end{array}$ & $\begin{array}{c}2.515 \\
(0.375,0.8,2.474)\end{array}$ & $\begin{array}{c}1.4995 \\
(0.7,0.55,2.4907)\end{array}$ \\
\hline
\end{tabular}

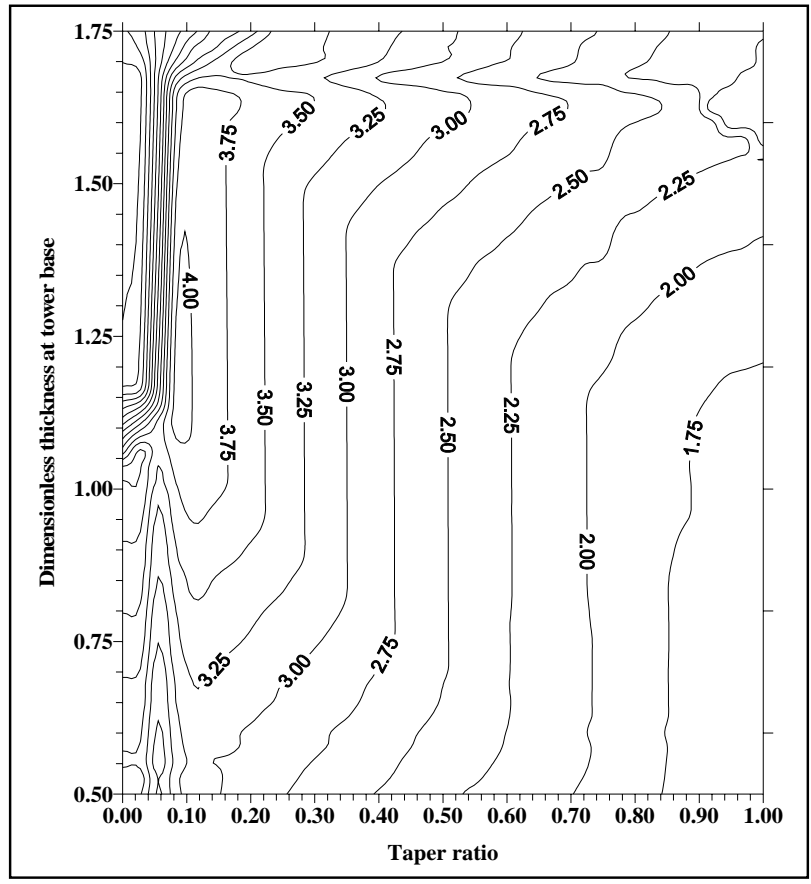

Fig. 4.a. $\hat{\mathrm{I}}_{\mathrm{N}}=0.001$ 


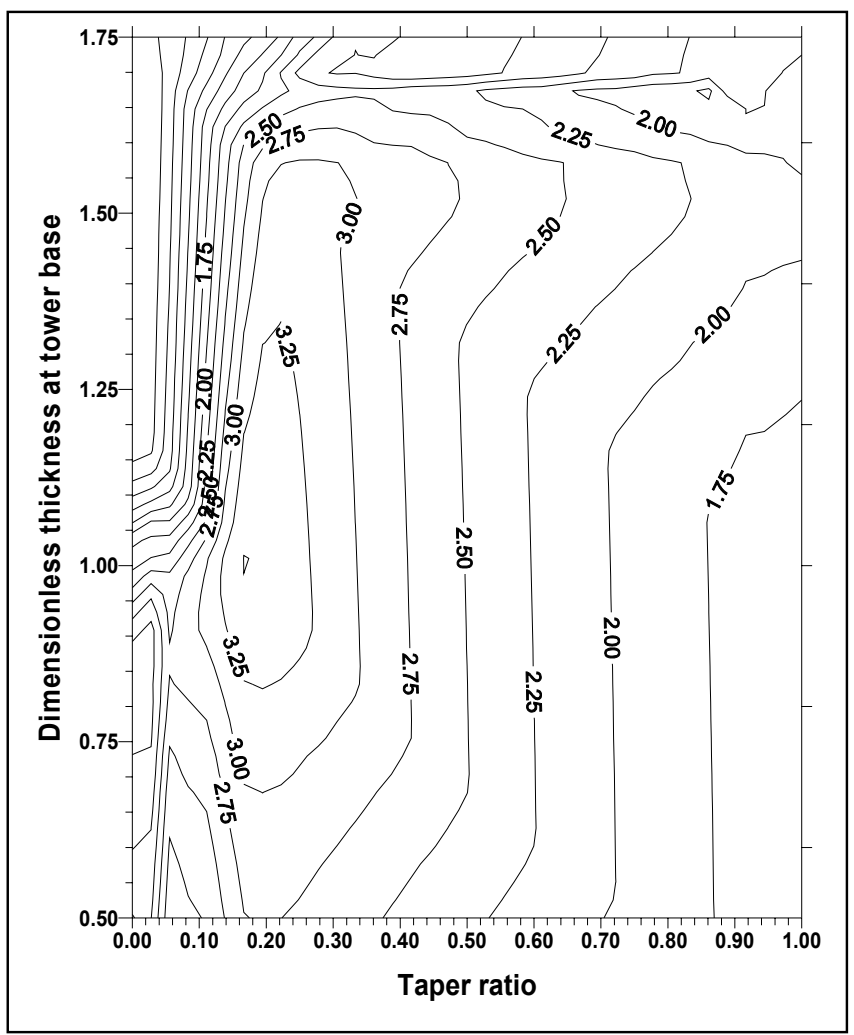

Fig. 4.b. $\hat{\mathrm{I}}_{\mathrm{N}}=0.01$

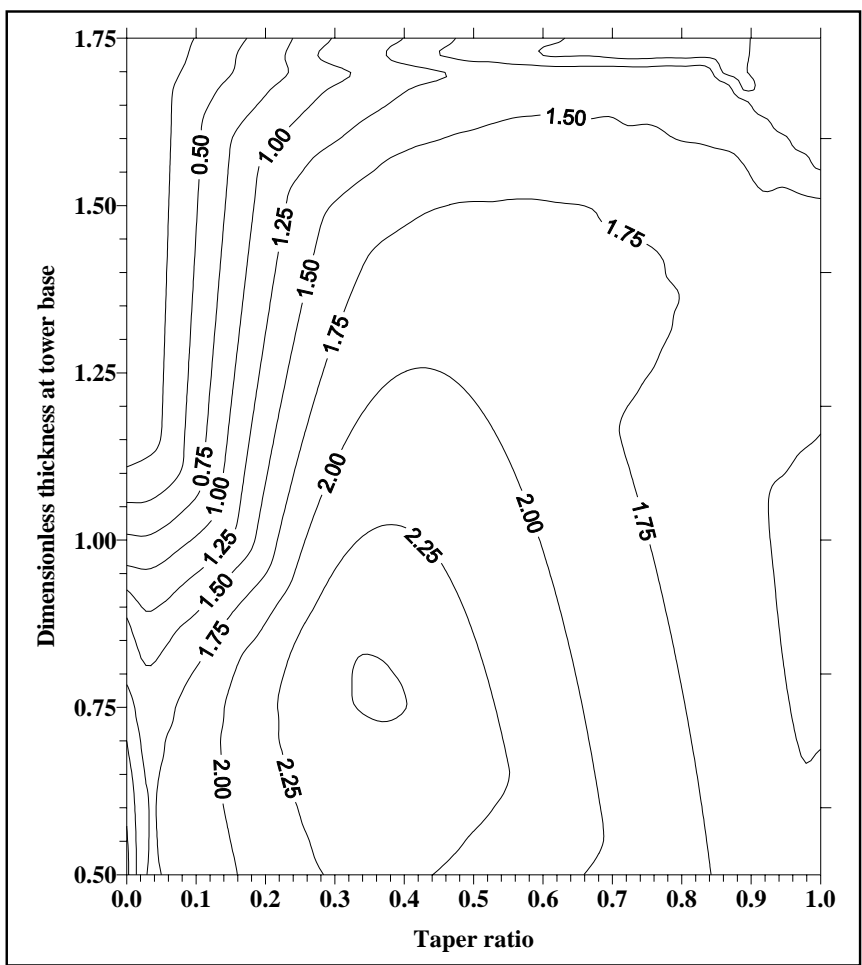

Fig. 4.c. $\hat{\mathrm{I}}_{\mathrm{N}}=0.1$ 


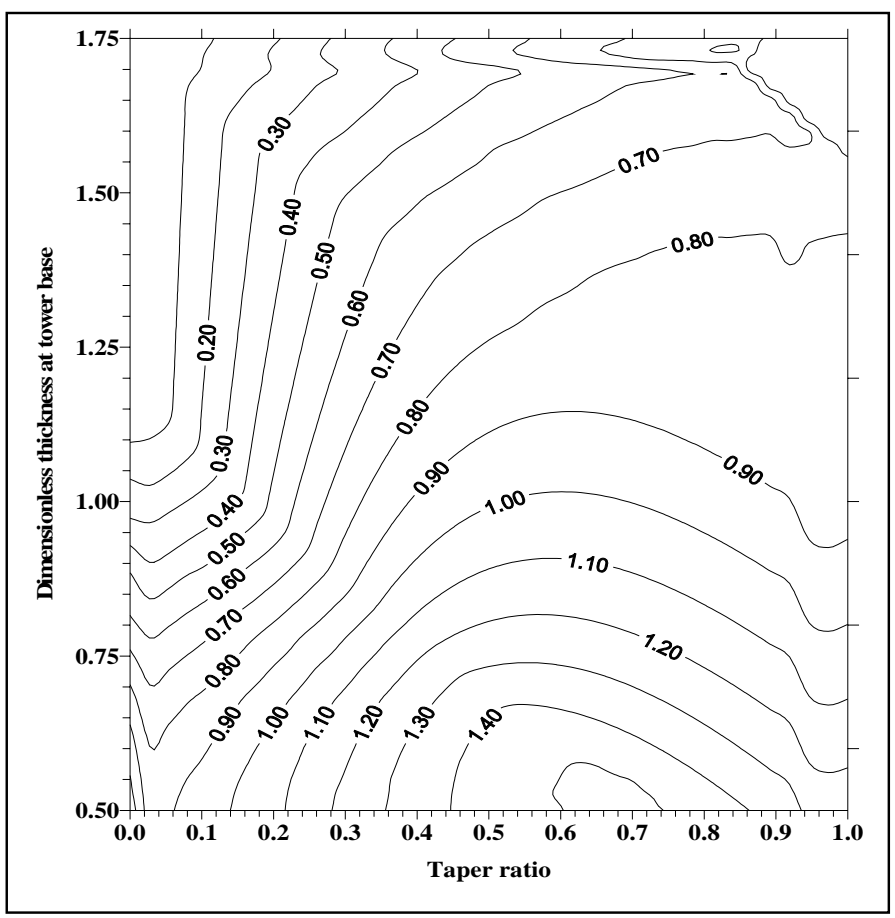

Fig. 4.d. $\hat{\mathrm{I}}_{\mathrm{N}}=1.0$

Fig. 4. Torsional frequency charts for the case of locked yawing mechanism, $(\hat{\mathrm{M}}=1)$.

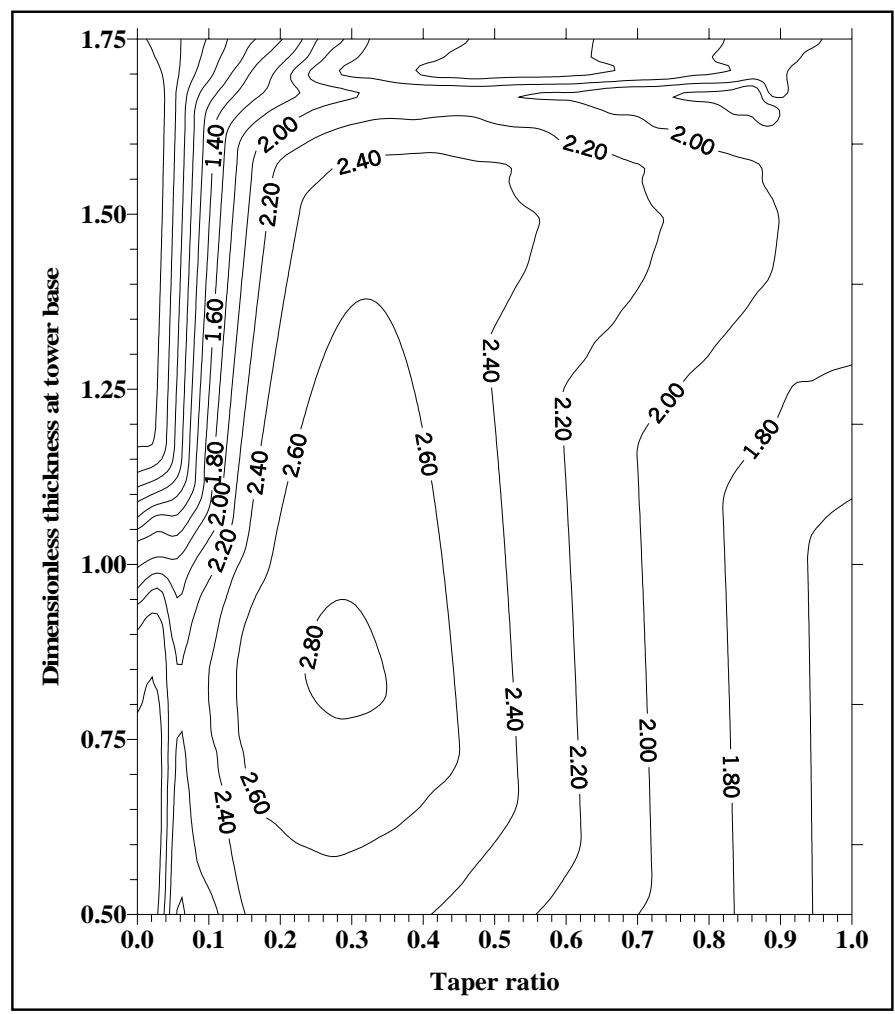

Fig. 5.a. $I_{N}=0.01 K_{y}=0.1$ 


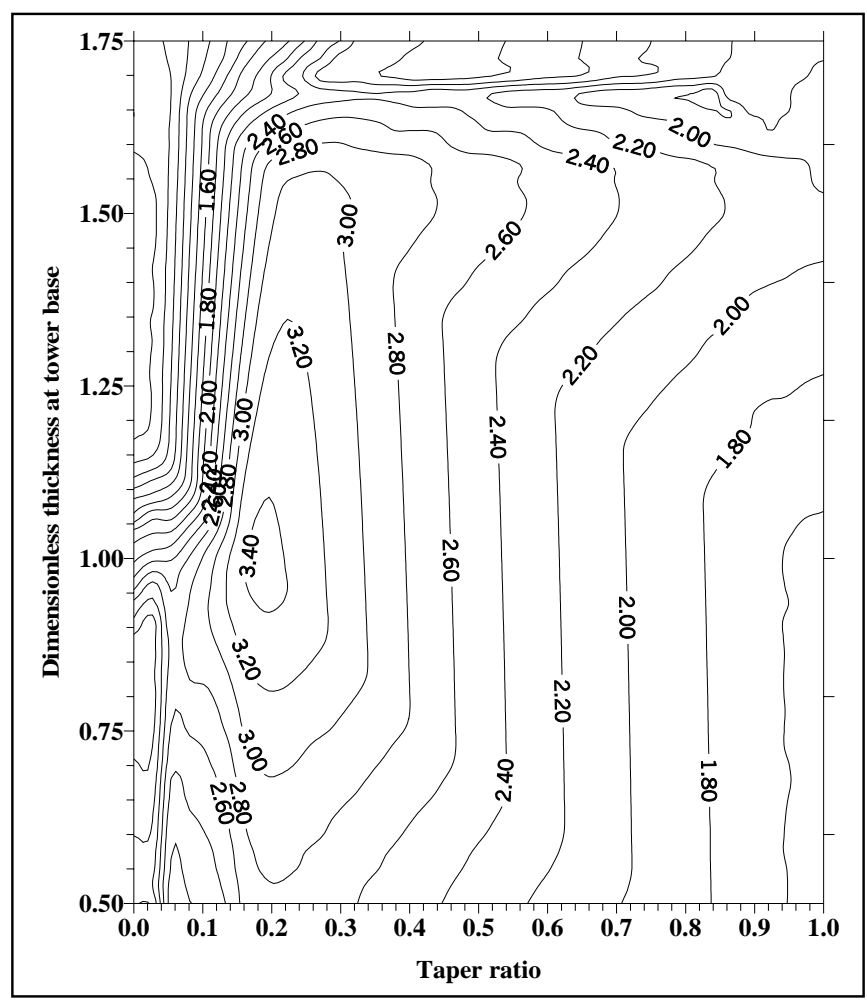

Fig. 5.b. $I_{N}=0.01 K_{y}=1.0$

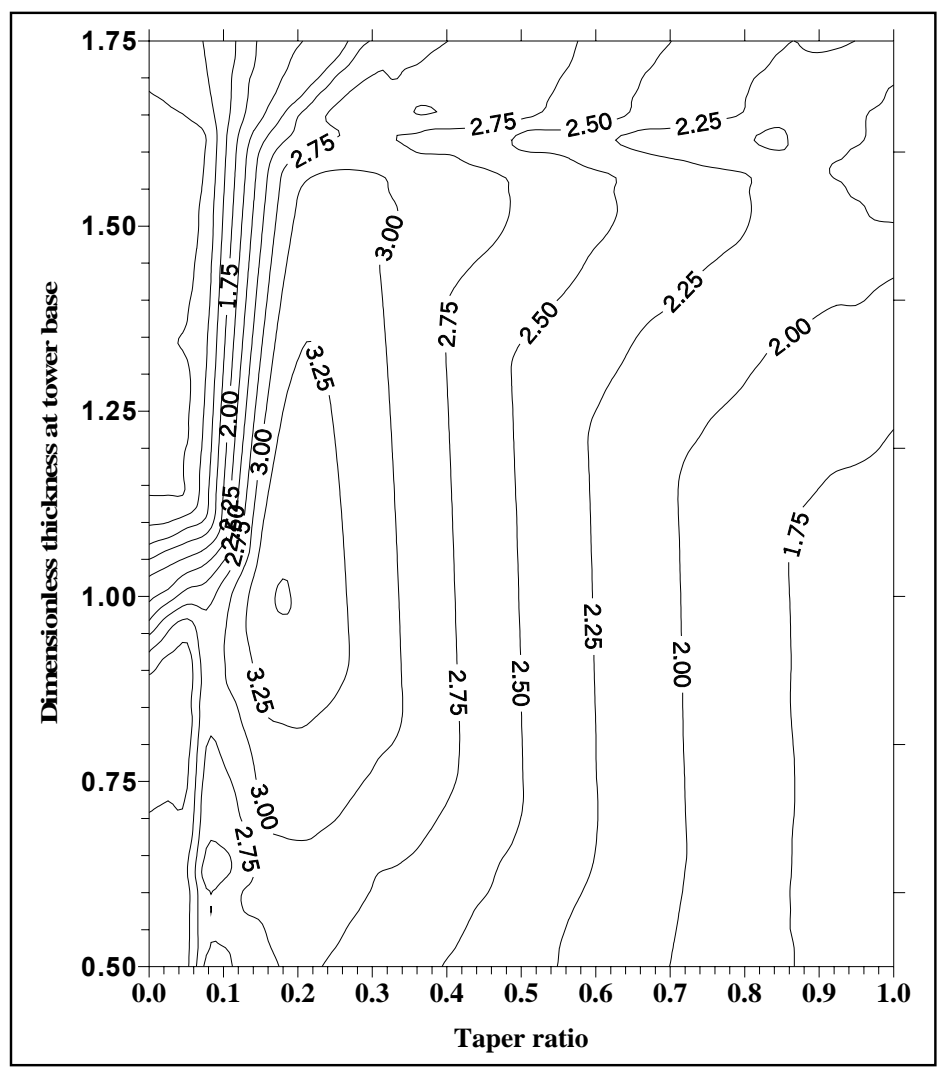

Fig. 5.c. $I_{N}=0.01 \quad K_{y}=10.0$ 


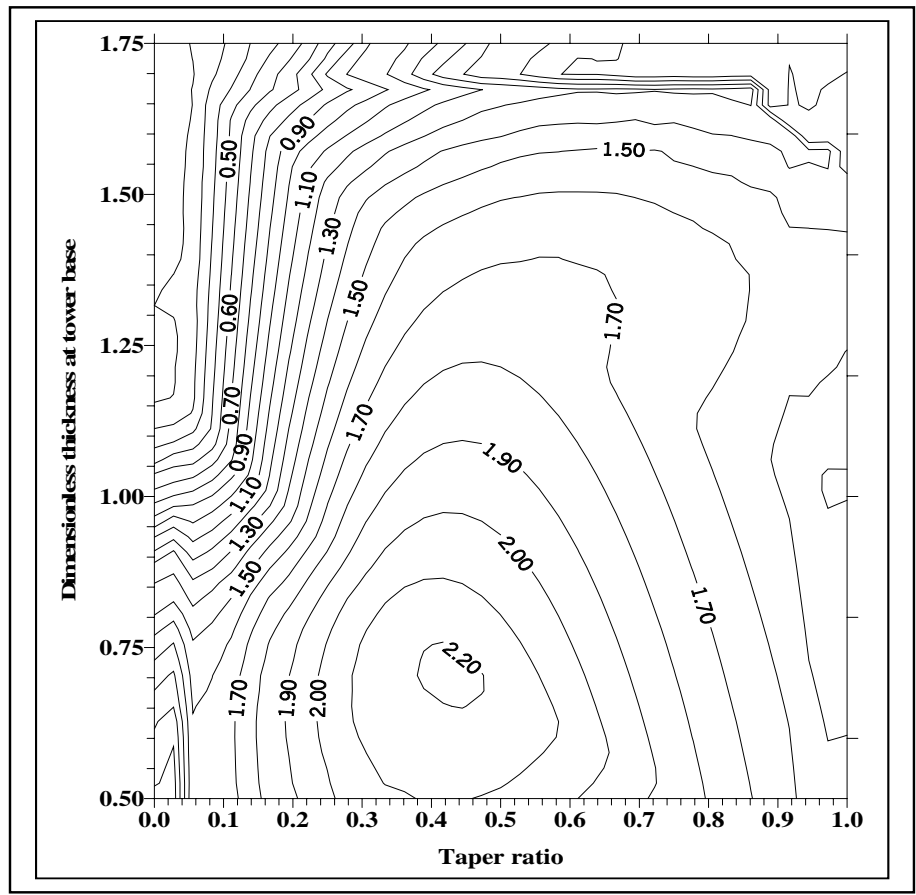

Fig. $5 . d . I_{N}=0.1 K_{y}=1.0$

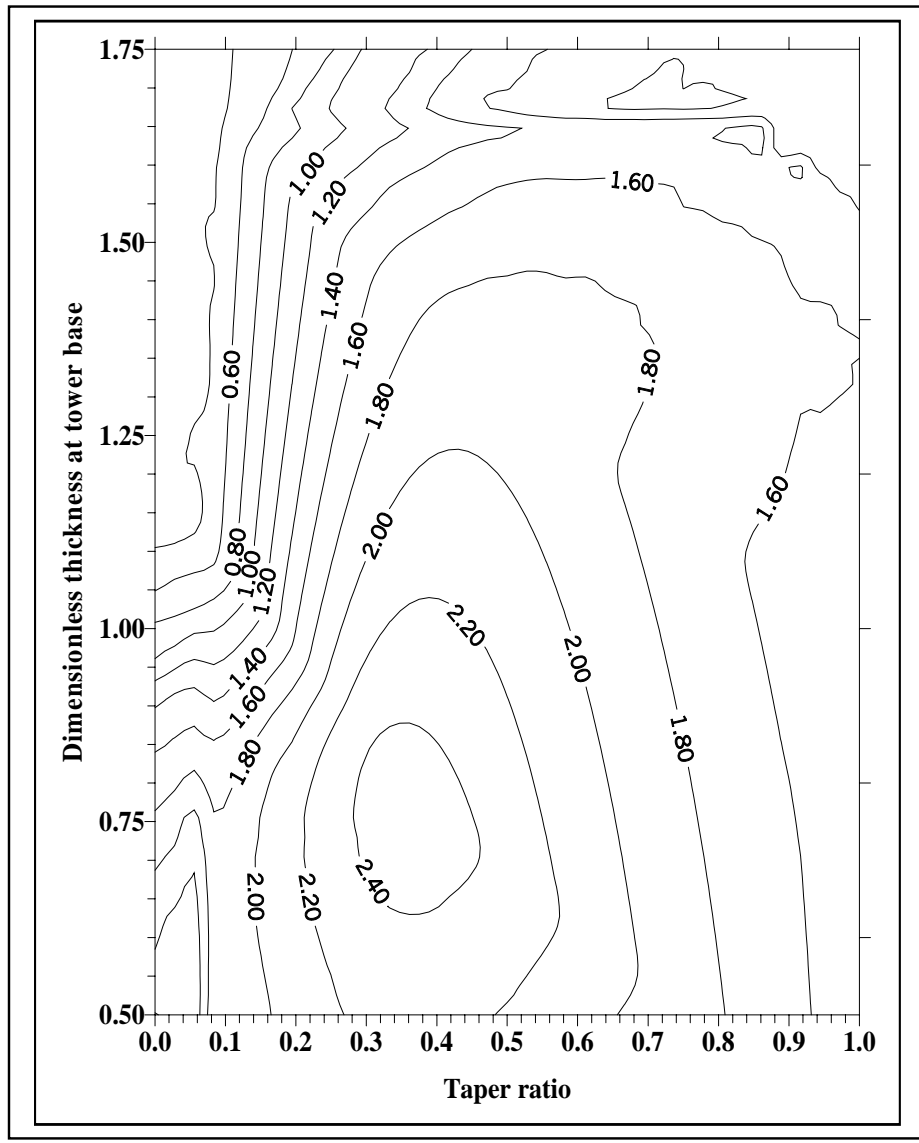

Fig. 5.e. $I_{N}=0.1 K_{y}=10.0$

Fig. 5. Torsional frequency charts for unlocked yawing mechanism, $(\hat{\mathrm{M}}=1)$. 


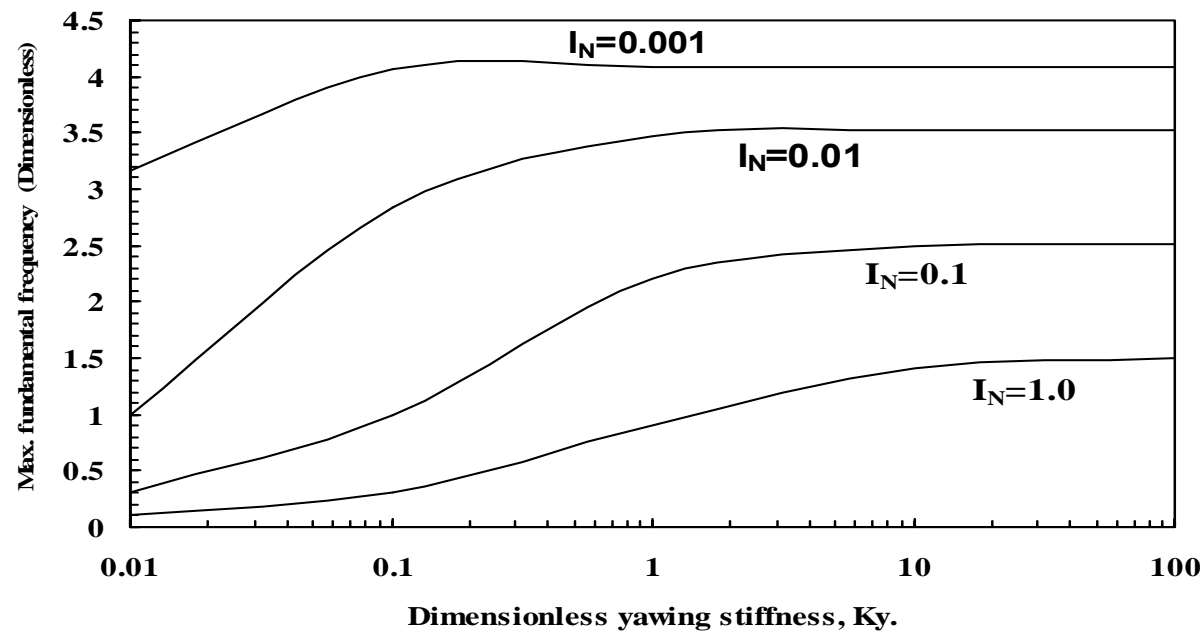

Fig. 6 Variation of the maximum fundamental frequency with yawing stiffness for different inertias of unlocked nacelle/rotor combination, $(\hat{\mathrm{M}}=1.0)$.

\section{CONCLUSIONS}

Efficient model for placing frequencies of a combined wind rotor/tower structure in free torsional motion has been presented in this paper.

The mathematical procedure implemented, combined with exact Bessel's function solutions, resulted in a beneficial tool that can be used for finding the optimal frequency design of a real-world wind turbine of any size and configuration. The model provides exact solutions to the vibration modes of a wind rotor/tower structure in free torsional motion, against which the efficiency of approximate methods, such as the finite element method, may be judged. Design variables include the tower tapering ratio, wall thickness and mean radius of the tower cross section.

Useful design charts for placing the frequencies at their desired (target) values has been developed for a prescribed total structural weight, and known nacelle/rotor inertia and spring stiffness of the yawing mechanism.

The fundamental frequencies can be shifted sufficiently from the range which resonates with the excitation frequencies.

There are other factors that ought to be considered in future investigations. For example, the system response due to sudden yaw motion, which may cause severe bending and shearing stresses within the blades and tower structures, should be analyzed and examined. Another natural extension of this work is to optimize the performance of a wind machine by simultaneously minimizing vibration level and structural weight using a muli-criteria optimization technique. 


\section{REFERENCES}

[1] Florin lov, Hansen A.D., Jauch C., Sorensen P., and Blaabjerg F., "Advanced Tools for Modeling, Design and Optimization of Wind Turbine Systems," Proceedings of NORDIC Wind Power Conference, Chalmers University of Technology, Goteborg- Sweden, 1-2 March, (2004).

[2] Thommy Ekelund, "Yaw Control for Reduction of Structural Dynamic Loads in Wind Turbines," Journal of Wind Engineering and Industrial Aerodynamics, Vol. 85, pp. 241-262, (2000).

[3] Bechly M.E., Gutierrez H., Streiner S. and Wood D.H., "Modeling the Yaw Behavior of a Small Wind Turbine," Wind Engineering, 26(4), pp. 223-239, (2002).

[4] Pesmajoglous S. and Graham J.M., "Yaw Loads on Horizontal Axis Wind Turbines using an Unsteady Vortex Lattice Method," Wind Energy Conversion: Proceedings of the $14^{\text {th }}$ British Wind Energy Association Conference, pp. 109-115, (1992).

[5] Peter D.A., Rossow M.P. and Timothy, "Design of Helicopter Rotor Blades for Optimum Dynamic Characteristics," J. of Computer and Mathematics with Applications, Vol. 12A, No.1, 1986.

[6] Pritchard J.I. and Adelman H.M., "Optimal Placement of Tuning Masses for Vibration Reduction in Helicopter Rotor Blades," AIAA J., Vol. 28, No. 2, 1990.

[7] Negm H.M. \& Maalawi K.Y., "Structural Design Optimization of Wind Turbine Towers," Journal of Computers \& Structures, vol.74, No. 6, pp. 649-666, February 2000.

[8] Maalawi K.Y. \& Negm H.M., "Optimal Frequency Design of Wind Turbine Blades," Journal of Wind Engineering \& Industrial Aerodynamics, Vol.90, No.8, pp.961-986, August, (2002).

[9] Shin Y.S., Haftka R.T. and Plaut R.H., "Simultaneous Analysis and Design of Eigenvalue Maximization", AIAA Journal, 26(6), pp. 738-744, (1988).

[10] Maalawi K.Y. \& El-Chazly N.M., Global Optimization of Multi-element Beam- Type Structures, The Second International Conference on Advances in Structural Engineering and Mechanics, ASEM'02, Busan, South Korea, August 21-23, (2002).

[11] Rao J.S., "Advanced theory of vibration," Wiley Eastern Limited, (1994).

[12] C.H. Edwards, JR. and David E. Penney, "Elementary differential equations with applications," Prentice-Hall, Inc., Englewood Cliffs, New Jersey, (1985).

[13] Haftka R. T., Gurdal Z, Kamat M. P., "Elements of structural optimization," Second edition, Dordrecht: Kluwer Academic Publishers, (1990).

[14] MSC / NASTRAN User's Manual, Version 63, Edit by C.W. Mc. McCormick, Mac Neal- Schwendler Corp., Los Angles, CA, (1984). 